\title{
5 Prime Nucleotidase Measurement
}

National Cancer Institute

\section{Source}

National Cancer Institute. 5 Prime Nucleotidase Measurement. NCI Thesaurus. Code C79437.

The determination of the amount of 5 prime nucleotidase present in a sample. 